\title{
TYPE 2 DIABETES MELLITUS PREDICTION IN MALAYSIA USING MODIFIED DIABETES RISK ASSESSMENT TOOL
}

\author{
Aung Myo Oo ${ }^{1}$, *Al-abed Ali Ahmed Al-abed², Ohn Mar Lwin ${ }^{3}$, Sowmya Sham Kanneppady ${ }^{4}$, Tee Yee Sim \\ Nor Ashikeen Mukti ${ }^{6}$, Anis Safirah Zahariluddin ${ }^{7}$ and Faizul Jaffar ${ }^{8}$ \\ ${ }^{1}$ Biochemistry Unit, Faculty of Medicine and Health Sciences, University Sultan Zainal Abidin, Jalan Sultan Mahmud,20400, \\ Kuala Terengganu, Malaysia. \\ ${ }^{2}$ Community Medicine Unit, Faculty of Medicine, Lincoln University College, 47301, Petaling Jaya, Selangor, Malaysia. \\ ${ }^{3}$ Physiology Unit, Faculty of Medicine, Lincoln University College, 47301, Petaling Jaya, Selangor, Malaysia. \\ ${ }^{4}$ Department of Pharmacology, Srinivas institute of Medical sciences and Research Centre, Mukka Surathkal, India \\ ${ }^{5}$ Department of Pharmacology, Faculty of Medicine and Health Sciences, Management and Science University, Malaysia. \\ ${ }^{6}$ Department of Biochemistry, Faculty of Medicine and Health Sciences, Management and Science University, Malaysia. \\ ${ }^{7}$ Department of Microbiology, Faculty of Medicine, University Kebangsaan Malaysia, Pekan Bangi, 43600 Bangi, Selangor, \\ Malaysia. \\ ${ }^{8}$ Department of Biochemistry, Faculty of Medicine, University Kebangsaan Malaysia, Pekan Bangi, 43600 Bangi, Selangor, \\ Malaysia.
}

Corresponding author: Al-abed Ali Ahmed Al-abed

Email: dr.abed.alabed@gmail.com

\section{ABSTRACT}

Type 2 diabetes mellitus (DM) is becoming major health threat worldwide and it is extremely common in clinical setting. Malaysia is one of the highest diabetic populations among Asian countries and the new cases are increasing day to day. Early detection of people with high risk of Type 2 DM by using simple, easy and cost-effective assessment tool is the better way to identify and prevent the community from this non-communicable disease. The objectives of the study were to identify those are high risk to become type 2DM among Malaysians by using risk scoring form and to educate them how to prevent it. Total 591 subjects were recruited from the health screening programs carried out by the collaboration of Petaling Jaya Development Council (MBPJ) and Lincoln University College, Malaysia. Modified form of Finnish Type 2 Diabetes Risk Assessment Tool was used to identify people at risk of becoming type 2 DM. Descriptive analysis was performed for all included variables in this study by using SPSS version 21. The study found out that almost half of the participants were found to have family history of DM, $60 \%$ of them were overweight and obese and $47 \%$ were having above normal waist circumference. We observed that nearly $60 \%$ of participants in the study were having moderate to high risk of becoming type 2 DM in next 10 years. To conclude, the result of our study would be helpful in implementation of costeffective, convenient Type 2 DM risk assessment tool which has yet to be implemented in Malaysia.

Keywords: Type 2 diabetes mellitus, assessment tool, health screening, prevention

\section{INTRODUCTION}

Global prevalence of type 2 diabetes mellitus (DM) is drastically increased, and it is extremely common in clinical setting. Diabetic population has risen from 108 million in 1980 to 422 million after 35 years especially in developing countries. It is also the leading cause of blindness, heart attack, stroke, renal failure and diabetic foot ulcer. According to World Health Organization (WHO), diabetes mellitus will be the seventh leading cause of death by 2030 (1). The number of diabetics will be increasing tremendously in South East Asia from 46 million in 2000 to 119 million by 2030(2). The fourth highest diabetic population in Asia is Malaysia based on the data (3). In 2006, there were total of 11.6 percent of diabetics in Malaysia and the number rose drastically to 15.2 percent of population in 2011 . The government had to spend billions of moneys for diabetic and diabetes related complications such as renal failure (4).

Selangor is located in the west coast of Peninsular Malaysia and surrounds Kuala Lumpur and Putra Jaya. Nearly 6.29 million people are residing in Selangor state whereas more than half a million people are residing in Petaling Jaya (5). Selangor is also Malaysia's most populous state and the largest number of diabetics was present in this state (6). Risk factors associated with type 2 DM are increasing age, family history, lack of exercise, overweight and increase waist size, high blood pressure, ethnicity, soft drink and impaired glucose tolerance. Many population-based studies have stated that there is strong link between family history and type 2 DM $(7,8)$. Similarly, researchers from various countries found out the stronger association between anthropometric markers and the incident of type $2 \mathrm{DM}(9,10,11)$. It has been 
frequently saying that people who consume sugary drinks (1-2 cans/day) have $26 \%$ greater risk of developing type 2 DM than those who rarely have such drink (12). Interestingly, hypertensive patients were found to have around $50 \%$ increase risk of developing type 2 DM (13). Researches have shown that there is association between the risk of type 2 DM and age $(14,15)$.

The questionnaires are simple and easy ways to identify people with high risk of type $2 \mathrm{DM}$. Finnish Type 2 Diabetes Risk Assessment Tool (FINDRISC) is an example of effective questionnaire that is being used for assessing type 2 diabetes risks (16). New cases of diabetic are increasing at alarming rate in Malaysia despite having various public health preventive measures. It is extremely important to create an assessment tool which is simple, noninvasive and cost-effective for early detection of type 2 DM. Proper and easily accessible screening method and appropriate education to risk group would be a prime way to deter the occurrence of new diabetic cases. Thus, this study aimed to identify who are at risk of type 2 DM by using modified diabetes risk assessment tool and to educate the high-risk people how to prevent or slow down this chronic disease.

\section{MATERIALS AND METHODS}

The cross-sectional descriptive study was conducted between 2015 and 2017 and total 591 subjects were participated in this study. Simple random sampling was used for the subject selection. The subjects were recruited from those attending the health screening programs carried out by the collaboration of Petaling Jaya Development Council (MBPJ) and Lincoln University College, Selangor, Malaysia. Inclusion criteria were age 18 years and above who gave consent to be included in the study. Pregnant women and subjects who were already diagnosed as DM were excluded in the study. Ethical approval was obtained from Ethical Committee, Research Management Centre of Lincoln University College. Health education was given by two medical professionals especially to those whose results showed moderate to high risks. Then, referral letter was issued to high risk groups to visit public medical centers in Petaling Jaya for further medical checkup.

Several type 2DM risk assessment scoring/screening tools are available such as American Diabetes Association, CPG guideline Malaysia for type 2DM, Finnish, Australian, Omani and Thai. The Finnish Type 2 Diabetes Risk Assessment Tool (FINDRISC) has long been using in various countries to identify the risks of type $2 \mathrm{DM}(16,17)$. In the present study, the modification of FINDRISC diabetes risk assessment tool as well as an adaptation of "screening of type 2 DM for asymptomatic individuals" from Clinical Practice Guideline (CPG) DM Malaysia was done and designed it into suitable for Malaysian population (18). The modified FINDRISC score was validated by a clinician, a statistician and a biochemist and it was found to be valid after administered to 35 selected staffs and students of LUC, Malaysia. The modified risk tool inclusive of age, family history of DM in first or second-degree relatives, history of hypertension and antihypertensive drug treatment, daily consumption of soft drink, daily physical activity, body mass index and waist circumference were used in the present study. Each category is assigned with weighed scores according to its associate risk and the final score range from 0 to 15 points. Every participant is classified according to their future risk of developing type 2 diabetes mellitus within next 10 years and the risk score is classified as less than 4 (low risk of type 2DM next 10 year), score 46 (moderate risk of type 2DM next 10 year) and score 7 and above (high risk of type 2DM next 10 year). The BMI used in this study is based on the obesity classification mentioned in Malaysia Clinical Practice Guideline (CPG) Obesity (19). The reference value for waist circumference is determined based on International Diabetes Federation guideline for Waist Circumference and Waist-Hip Ratio for Asians (20).

The weight was measured to the nearest $0.1 \mathrm{~kg}$ and the height was measured to the nearest $0.1 \mathrm{~cm}$ by using stadiometer attached to the same medical balance weighing scale. The BMI was calculated by using the formula (weight in $\mathrm{kg} /$ height in $\mathrm{m} 2$ ). Waist circumference was measured by a nonstretchable tape measure at a level of midpoint between the lowest rib and iliac crest to the nearest $0.1 \mathrm{~cm}$ (umbilical line). Descriptive analysis was performed for all included variables in this study by using SPSS version 21.

\section{RESULT}

Table 2 showed that $56.5 \%$ representing majority of the respondents (age below 40) compared to other groups. Most of the respondents were female $57.7 \%$ vs $42.3 \%$ for male. It was shown that most of the respondents' parents who are not diabetic were slightly higher compared to those who are diabetic $54.3 \%$ vs $45.7 \%$. Those who are not having any hypertension/ hypertensive treatment were the majority $(82.9 \%)$ compared to those who are having hypertension and its treatment (17.1\%).

The waist measurement was taken for all respondents and found that $53.0 \%$ of them were with normal waist compared to other categories. Moreover, most of them were in normal BMI representing $40.1 \%$ vs $59.9 \%$ for overweight and obese. 
It was demonstrated that $58.7 \%$ of the respondents have never consumed any soft drink while $34.7 \%$ consumed 3-4 cans weekly and $6.6 \%$ consumed 1 can and more per day. Exercise was measured and categorized to 3 groups: not at all, less than 30 $\mathrm{min} /$ day and more than $30 \mathrm{~min} /$ day representing $31.5 \%, 50.9 \%$ and $17.6 \%$ respectively.
After calculation the overall score from all included variables, most of the respondents were less likely to have diabetes in the next 10 years as they scored less than 4 points with $40.6 \%$. On the other hand, $36.2 \%$ and $23.2 \%$ of them have moderate and high risk respectively to have diabetes in the next 10 years.

Table 1: Type 2 diabetes mellitus risk assessment form

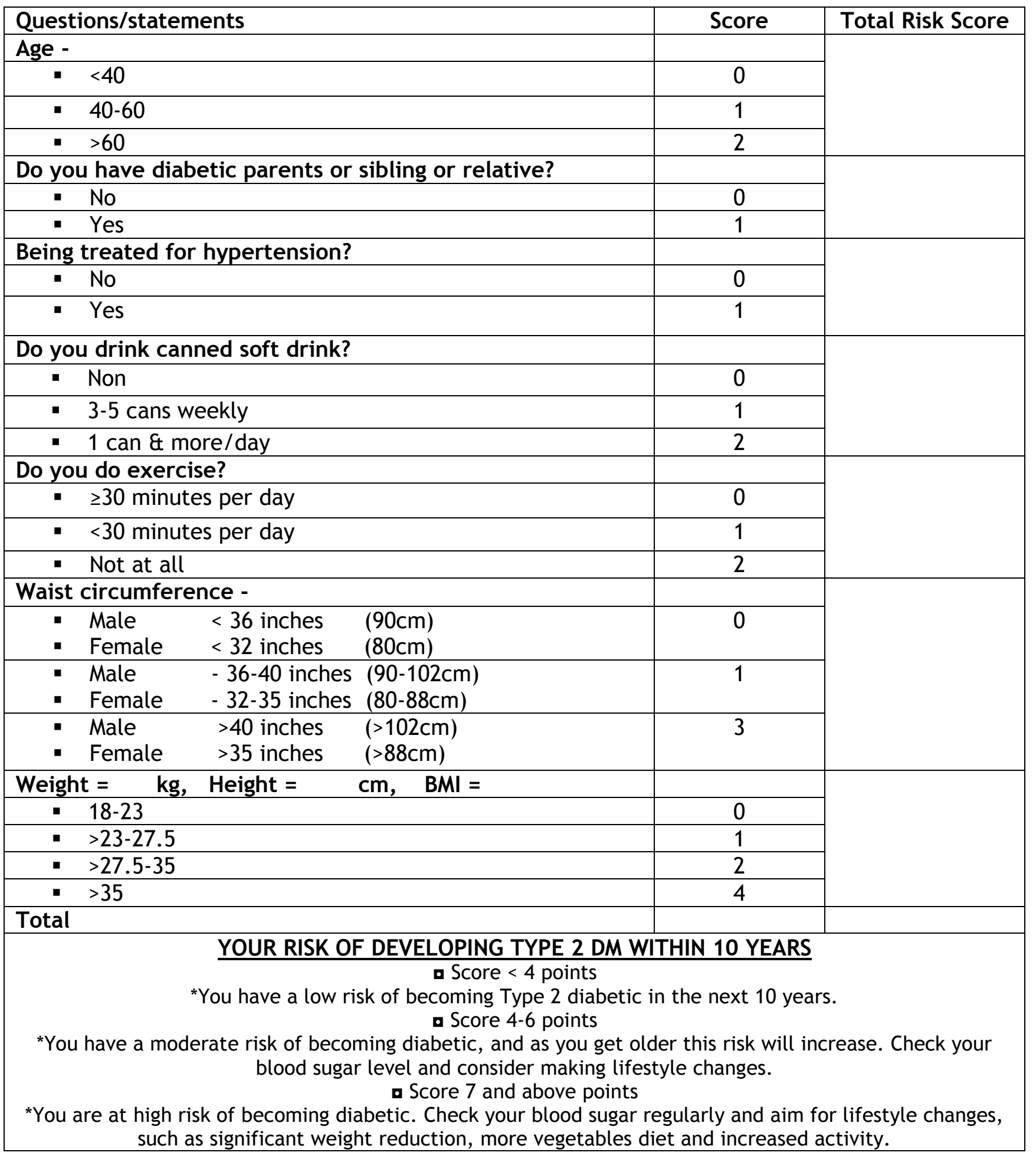


Table 2: Descriptive analysis for all included variables

\begin{tabular}{|c|c|c|}
\hline Variable & Frequency & Percentage \% \\
\hline \multicolumn{3}{|l|}{ Age } \\
\hline Less than 40 & 334 & 56.5 \\
\hline $40-60$ & 194 & 32.8 \\
\hline More than 60 & 63 & 10.7 \\
\hline \multicolumn{3}{|l|}{ Sex } \\
\hline Male & 250 & 42.3 \\
\hline Female & 341 & 57.7 \\
\hline \multicolumn{3}{|l|}{ Diabetic parents } \\
\hline Yes & 270 & 45.7 \\
\hline No & 321 & 54.3 \\
\hline \multicolumn{3}{|l|}{ Hypertension treatment } \\
\hline Yes & 101 & 17.1 \\
\hline No & 490 & 82.9 \\
\hline \multicolumn{3}{|l|}{ Waist } \\
\hline 1 (Male-<90cm, Female $\quad-<80 \mathrm{~cm})$ & 313 & 53.0 \\
\hline $\begin{array}{c}2 \text { (Male }-90-102 \mathrm{~cm} \text {, Female }-80- \\
88 \mathrm{~cm})\end{array}$ & 175 & 29.6 \\
\hline $3($ Male $->102 \mathrm{~cm}$, Female $->88 \mathrm{~cm})$ & 103 & 17.4 \\
\hline \multicolumn{3}{|l|}{ ( } \\
\hline $18-23$ & 237 & 40.1 \\
\hline$>23-27.5$ & 203 & 34.3 \\
\hline$>27.5-35$ & 119 & 20.1 \\
\hline$>35$ & 32 & 5.4 \\
\hline \multicolumn{3}{|l|}{ Soft drink } \\
\hline Non & 347 & 58.7 \\
\hline 3-5 cans weekly & 205 & 34.7 \\
\hline 1 can \& more/day & 39 & 6.6 \\
\hline \multicolumn{3}{|l|}{ Exercise } \\
\hline Not at all & 186 & 31.5 \\
\hline Less than $30 \mathrm{~min} /$ day & 301 & 50.9 \\
\hline More than $30 \mathrm{~min} /$ day & 104 & 17.6 \\
\hline \multicolumn{3}{|l|}{ Risk score } \\
\hline Less than 4 points & 240 & 40.6 \\
\hline 4-6 points & 214 & 36.2 \\
\hline $7 \&$ more & 137 & 23.2 \\
\hline
\end{tabular}

\section{DISCUSSION}

Millions of people in the world today have dangerously high blood sugar level and do not yet know it. The Health Minister of Malaysia said that $30 \%$ of the nation's citizens were overweight and this was due to an unhealthy diet and lifestyle. Nearly $17.5 \%$ of the people were also diabetic and some of them did not even know that they were afflicted with the problem (21). Almost half of the participants in the present study were found to have family history of DM. Genetic factor causing type 2 DM is a major non-modifiable risk factor that cannot be changed. A study done in Europe has mentioned that family history was associated with the higher incidence of type 2DM. The researchers also observed that greatest risk of type 2DM was found in those with a biparental history of the disease (22). A group of researchers in Malaysia also agreed that there was association between positive family history and type 2 DM. They reported that $50.2 \%$ of patients had family history of DM (23).

In the present study, the modifiable risk factors such as BMI and waist circumference play major role in increasing the risk score as $34 \%$ and $25.5 \%$ of participants were overweight and obese, respectively. Our findings were consistent with another study carried out in Malaysia where the researchers mentioned that $51.2 \%$ of participants were overweight and obese although they were having mild physical activity (24). Although majority of participants were age below 40 in this study, we observed high number of overweight and obese people. Studies conducted by Nutrition Society of Malaysia endorsed that almost 30\% of children and teenagers age between six and 17 years were either overweight or obese. It concluded that the cause of overweight and obesity are due to easily accessible to junk food and drinks, eating high trans-fat and sugar content as well as lack of 
exercise and sedentary inactive lifestyle (longtime playing of games, using social media and watching movies). Researchers also warned that proper action should be taken immediately to lessen or deter the problem otherwise it may not only hamper the quality of life but also lead to risk of having secondary complications like type $2 \mathrm{DM}$ and cardiovascular problem (25).

Many researchers have confirmed that the changes in fat metabolism in obesity causing higher level of non-esterified fatty acids in the blood which decrease cellular insulin responsiveness and leading to hyperglycemia. Likewise, increased production of pro-inflammatory cytokines from abdominal fat also causing insulin resistance which is the hallmark of type $2 \mathrm{DM}(26,27)$.

Encouragement of the public to be involved in physical activities becomes very crucial because the vast numbers of participants in the study were not doing exercise $(31.5 \%)$ or having inadequate physical activity (51\%). Although genetic factor plays a role in the occurrence of type $2 \mathrm{DM}$, the progression of type 2 DM would be prevented or delayed by practicing active lifestyle which could reduce blood sugar and improve insulin sensitivity.

It is very worrisome for the nation as the number of obese people and type2 DM patients are growing drastically day to day as well as healthcare cost is also becoming a burden for the country. The best way in preventing or slowing down of impending type $2 \mathrm{DM}$ is to find out who are at risk by frequently doing health check of the population in township, state and national levels and do proper screening for high risk people as described in Malaysia clinical practice guideline (CPG) for DM (18). A group of researchers from Nursing College, Sultan Qaboos University, Oman has carried out a study on "Riskassessment score for screening diabetes mellitus among Omani adults and they have concluded that the risk assessment (FINDRISC) of type 2 DM was significant and positively related to the prediction of type 2DM among Omani adults (28).

Our study has found that more than $59 \%$ of participants in the study were having moderate to high risk of becoming type $2 \mathrm{DM}$ in next 10 years (moderate risk 36.2\% and high risk 23.2\% respectively) based on the test score. Similar findings were observed in a study done in Pakistan where they used FINDRISC assessment tool and they found that almost $47 \%$ of participants were having moderate to high risk of developing type 2DM in next ten year (29). A group of researchers from Thailand has implemented Thai type 2DM risk assessment tool using the variables such as age, sex, BMI, waist circumference, history of high blood pressure and family history of DM. They have proved that simple assessment tool without laboratory test is almost as good as models that include fasting glucose, HDL cholesterol and triglycerides. They have also mentioned that the assessment tool is attractive because of non-invasive, more convenient and less expensive compared with the models that rely on blood tests. The assessment tool is also practical for identifying high risk people (not for confirmation of diagnosis) in primary health care setting (30).

In the present study, moderate to high risk participants were consulted and explained how to practice healthy lifestyle and educated them to do regular check-up. The referral letters were issued to those who were in high risk group to do medical check-up in health clinic. To prevent the growing number of obesity and type $2 \mathrm{DM}$, not only the individual and family members but also the local counsel, healthcare professionals and state government need to take proper action in prevention of one of the major non-communicable diseases, type 2 DM in Malaysia.

\section{CONCLUSION}

The study concluded that majority of participants have moderate to high risk of developing type $2 \mathrm{DM}$ mostly associated with obesity and family history. Changing eating habit and lifestyle modification are vital information which need to be addressed promptly and immediately. As the incidence of type 2 DM among Malaysian adults increases drastically despite measures to slow down, it is very crucial time for healthcare personals to be able to identify people who are at risk by using simple and appropriate type2 diabetes risk assessment tool and empowering them with life style modification to prevent or delay the onset of type 2 DM. Further modification of this assessment tool should be done by experts to develop a better assessment tool suitable for Malaysian population.

\section{Limitation}

This study is limited by cross-sectional study design and some factors such as ethnicity and previous history of high blood glucose and blood cholesterol level were not included in the assessment form. Validation of the assessment tool with larger sample size in different populations would have done to have a more reliable assessment tool.

\section{Acknowledgement}

We express our sincere gratitude to Dean, Faculty of Medicine, Lincoln University College and the authorities from MBPJ for their kind help and arrangement for the successful health screening events. The authors show their heartiest thanks to all participants who gave their consent to be involved in the study voluntarily. 


\section{Conflict of Interest \\ None declared}

\section{REFERENCES}

1. Mathers CD and Loncar D: Projections of global mortality and burden of disease from 2002 to 2030. PLoS Med, 2006, 3(11): e442.

2. International Diabetes Federation One adult in ten will have diabetes by 2030 . November 14, 2011. Available from http://www.idf.org/mediaevents/press-releases/2011/diabetesatlas-5th-edition

3. The Sun daily. Malaysia has fourth highest diabetics in Asia. November 2016, Available from http://www.thesundaily.my/news/2057 274

4. The Star online. Alarming increase in diabetes among Malaysians., April 2016, Available from http://www.thestar.com.my/news/nati on/2016/04/08/hilmi-alarmingincrease-in-diabetes-amongmalaysians/\#HHxWJkelbyj5HBJy.99

5. "Population by States and Ethnic Group". Department of Information, Ministry of Communications and Multimedia, Malaysia. 2015. Archived from the original on 12 February 2016. Available from

https: / /web.archive.org/web/20160212 125740/http:/pmr.penerangan.gov.my/ index.php/info-terkini/19463-unjuranpopulasi-penduduk-2015.html

6. Non-Communicable Disease Section Disease Control Division Ministry of Health Malaysia National Diabetes Registry Report Volume 1 2009-2012

7. Hariri S, Yoon PW, Moonesinghe R, Valdez R and Khoury MJ. Evaluation of family history as a risk factor and screening tool for detecting undiagnosed diabetes in a nationally representative survey population. Genet Med. 2006 Dec; 8(12):752-9.

8. Das M, Pal S, and Ghosh A. Family history of type 2 diabetes and prevalence of metabolic syndrome in adult Asian
Indians. Journal of Cardiovascular Disease Research, 2012, 3(2), 104-108.

9. Awasthi A, Rao CR, Hegde DS, et al. Association between type 2 diabetes mellitus and anthropometric measurements - a case control study in South India. Journal of Preventive Medicine and Hygiene, 2017, 58(1), E56E62.

10. Gray N, Picone G, Sloan F, et al. The Relationship between BMI and Onset of Diabetes Mellitus and its Complications. Southern Medical Journal, 2015,108(1), 29-36.

11. Hartwig $S$, Kluttig A, Tiller $D$, et al. Anthropometric markers and their association with incident type 2 diabetes mellitus. Which marker is best for prediction? BMJ Open. 2016 Jan 20; 6(1): e009266. Epub 2016 Jan 20.

12. Malik VS, Popkin BM, Bray GA, et al. Sugar-sweetened beverages and risk of metabolic syndrome and type 2 diabetes: a meta-analysis. Diabetes Care. 2010;33: 2477-83.

13. Bazian: High blood pressure: does it lead to diabetes? NHS Choices Thursday October 12015. https://www.nhs.uk/news/diabetes/hi gh-blood-pressure-does-it-lead-todiabetes/

14. Centers for Disease Control and Prevention. National diabetes fact sheet: national estimates and general information on diabetes and prediabetes in the United States, 2011. Atlanta:U.S. Department of Health and Human Services, Centers for Disease Control andPrevention.

15. Suastika K, Dwipayana P, Saraswati IMR, et al. Relationship between age and metabolic disorder in the population of Bali. J Clin Gerontol Geriatrics 2011, 30: 1-6.

16. Lindstrom $\mathrm{J}$ and Tuomilehto J. The diabetes risk score: a practical tool to predict type 2 diabetes risk. Diabetes Care 2003. 26:725-731.

17. Australian type 2DM risk assessment tool (AUSDRISK) Available from https://static.diabetesaustralia.com.au 
/s/fileassets/diabetesaustralia/6d252140-1ff0-47b2-a83f$3 c c 3 d b 348131 . p d f$

18. Clinical practice guidelines management of type 2 diabetes mellitus,2015 (5th Edition). Available from http://www.moh.gov.my/penerbitan/C PG/CPG\%20T2DM\%202015.pdf

19. Clinical practice guideline for obesity, Malaysia 2004. Available from http://www.moh.gov.my/penerbitan/C PG2017/3932.pdf

20. Waist Circumference and Waist-Hip Ratio: Report of a WHO Expert Consultation Geneva, 8-11 December 2008. Available from http://apps.who.int/iris/bitstream/106 65/44583/1/9789241501491_eng.pdf

21. Obesity, A growing problem. The Star News, May 2016. Available from http://www.thestar.com.my/news/nati on/2016/05/02/obesity-a-growing problem/\#dGLjcZqWQ216fgK0.99

22. Scott RA, Langenberg C, Sharp SJ, et al: The link between Family History and risk of Type 2 Diabetes is Not Explained by Anthropometric, Lifestyle or Genetic Risk Factors: the EPIC-InterAct Study; Diabetologia. 2013 January; 56(1): 6069. doi:10.1007/s00125-012-2715-x.

23. Hussein Z, Taher SW, Singh HKG and Swee WCS: Diabetes Care in Malaysia: Problems, New Models, and Solutions; Annals of Global Health,2015; vol. 81, no. 6, 2015.

24. Chan YY, Lim KK, Lim KH, Teh CH, Kee CC, Cheong SM, et al. Physical activity and overweight/obesity among Malaysian adults: findings from the 2015 National Health and morbidity survey (NHMS). BMC Public Health,2017, 17, 733. http://doi.org/10.1186/s12889017-4772-z

25. Malaysia at risk of becoming a chubby nation. The News Strait Times; May 2016. Available from http:/ /www.nst.com.my/news/2016/05 /143258/malaysia-risk-becomingchubby-nation

26. Jelic K, Luzio SD, Dunseath G, ColdingJorgsensen $M$ and Owens DR. A cross- sectional analysis of NEFA levels following standard mixed meal in a population of persons with newly diagnosed type 2 diabetes mellitus across a spectrum of glycemic control: American Diabetes Association; 2007. Available from: http://professional.diabetes.org/Abstra cts_Display.aspx?

27. Kahn SE, Hull RL and Utzschneider KM. Mechanisms linking obesity to insulin resistance and type 2 diabetes. Nature. 2006 Dec 14; 444(7121):840-6.

28. D' Souza MS, Amirtharaj A, Venkatesaperumal $R$, et al : Riskassessment score for screening diabetes mellitus among Omani adults; SAGE Open Med. 2013; 1: 2050312113508390

29. Ishaque A, Shahzad F, Muhammad F, et al. Diabetes risk assessment among squatter settlements in Pakistan: A cross-sectional study. Malaysian Family Physician: The Official Journal of the Academy of Family Physicians of Malaysia, 2016; 11(2-3), 9-15.

30. Aekplakorn W, Bunnag P, Woodward M, et al.: A risk score for predicting incident diabetes in the Thai population. Diabetes Care. 2006 Aug;29(8):1872-7. 